\title{
Prevalence Of Developmental Oral Mucosal Lesions Among A Sample Of Denture Wearing Patients Attending College Of Dentistry Clinics In Aljouf University
}

\author{
Abdalwhab M.A.Zwiri \\ Assistant professor of oral medicine, \\ Aljouf University, Sakaka, Aljouf, Saudi Arabia \\ Santosh Patil \\ Assistant professor of Radiology, \\ Aljouf University, Sakaka, Aljouf , Saudi Arabia \\ Fadi AL-Omair \\ Intern dentist, Aljouf University, Sakaka, Aljouf , Saudi Arabia \\ Mohammed Assayed Mousa
}

Lecturer of prosthodontics, Aljouf University, Sakaka, Aljouf , Saudi Arabia Ibrahim Ali Ahmad

Department of Dentistry, AlWakra Hospital,

Hamad Medical Corporation, AlWakra, Qatar

doi: 10.19044/esj.2016.v12n24p352 URL:http://dx.doi.org/10.19044/esj.2016.v12n24p352

\begin{abstract}
Introduction: developmental oral lesions represent a group of normal lesions that can be found at birth or evident in later life. These lesions include fissured and geographic tongue, Fordyce's granules and leukoedema. Study aims: to investigate the prevalence of some developmental oral mucosal lesions among dental patients wearing dentures who were attending college of dentistry clinics in Aljouf University, and specialized dental center of ministry of health.

Methods and subjects: a retrospective design was conducted to collect data from 344 wearing denture dental patients who were attending college of dentistry clinics in Aljouf University, and specialized dental center of ministry of health. A working excel sheet was created for patients and included data related to personal information such as age and gender; and oral developmental lesions. The software SPSS version 20 was used to analyze data. Statistical tests including frequency, percentages, and One way Anova were used to describe data. Significance was considered at alpha level $\leq 0.05$.
\end{abstract}


Study findings: the majority of participants were males (86\%), the mean age was $51.60+3.51$ years. The prevalence of fissured tongue was $10.2 \%$, geographic tongue $11.3 \%$, Fordyce's granules $7 \%$, and leukoedema $7.3 \%$. Age was significantly associated with fissured tongue $(\mathrm{p}=0.04)$, and Fordyce's granules ( $\mathrm{p}=0.003$ ). Gender was not associated significantly with any of the studied lesions.

Conclusion: developmental oral lesions among dental patients wearing dentures exist with varying rates of prevalence as well as it provides valuable basic data about the prevalence of oral mucosal lesions among patients seeking dental care in Aljouf area.

Keywords: Oral lesions, fissured tongue, geographic tongue, leukoedema, Fordyce's granules

\section{Introduction}

Oral mucosa acts as a barrier to offer protection against a variety of adverse conditions including the exposure to carcinogenic materials, pathogenic organisms and trauma. Accordingly, it can be under the influence of different lesions and conditions which can be either harmless or serious complications (Langlais et al., 2009).

Some oral lesions including fissured and geographic tongue, oral mucosal Fordyce's granules and leukoedema are developmental oral lesions and considered as normal conditions rather than pathological lesions (Shafer et al., 1983). It is possible to have these lesions at birth, or become evident later in life. Usually, these lesions are discovered during routine dental examination and vary depending on age, gender and/or race (Reichart, 2000; Martin, 1997; Kullaa, 1988; Axell and Henricsson., 1981). Irrespective to the consideration that these lesions are harmless, some studies reported a clear relationship between these developmental conditions and environmental effects (Van Wyk, 1985; Reichart et al., 1987).

\section{Fordyce's spots}

The first report describing whitish spots in various anatomical sites including vermilion border of the lips, oral mucosa and, genital mucosa was made by Fordyce (1986). Further studies showed that these spots are ectopic sebaceous glands (James et al., 2006; Taylor et al., 2007; Ahmed et al., 2009). From a clinical point of view, Fordyce's spots are as small whitish or yellowish papules (Drore and Sexton, 1996). Fordyce's spots can be found in various sites within the oral cavity including the upper lip vermilion (Dover et al., 1996), retromolar area and buccal mucous (Drore and Sexton, 1996). 
Fordyce's spots can influence both genders and their prevalence was estimated to be 80\% of patients (Dover et al., 1996; Drore and Sexton, 1996; Elder, Elenistas and Ragsdale, 1997; Hashimoto and Lever, 1999).

Lee et al (2012) conducted a study including 16 Korean patients with Fordyce's spots. Out of these patients, there were 16 males, and the average age was 34.3years.

Jorge et al (2003) introduced a new technology to treat Fordyce's spots $\mathrm{CO} 2$ by superpulsed laser and this technique was found as a safe and effective treatment offering excellent cosmetic results.

\section{Fissured tongue}

Fissured tongue is considered one of the inherited diseases with varied size and depth grooves. No specific etiology has been identified, although an inheritance polygenic mode has been suggested. It is asymptomatic unless there is a collection of debris within fissure occurs (Goswami et al., 2012).

Fissured tongue is characterized by being prevalent, benign, and subclinical disorder with hollows that spread along various parts of the tongue including the lateral and dorsum parts of the tongue with varying degrees of depth (Musaad et al., 2015). It has been reported that Fissured tongue is prevalent among individuals with a mental problems including Down's syndrome, Melkerson-Resenthal Syndrome and Trisomy (Goswami et al., 2012). According to Nevelle et al (2004), The protective filiform papilla of tongue are reduced in fissured tongue which may lead to inflammation.

\section{Geographical tongue}

Geographic tongue is called "benign migratory glossitis" (Musaad et al., 2015). It is not malignant from a pathological point of view and leads to damage of filiform papillae which is manifested by a change in taste sensation and feeding problems (Mdel et al.,2005). It is thought that geographical tongue is developed due to the occurrence of disturbances during the 4th week of intrauterine life (Khozeimeh and Rasti, 206; Sadler, 2011).

Geographic tongue is associated with recurrent appearance and resolution of irregular, smooth red patches in the tongue (Cawson, 2008). It has no known etiology, but it is possible that it is due to hereditary or secondary to other conditions including psoriasis, vitamin B12 or zinc deficiency (Cawson, 2008). 


\section{Leukoedema}

Leukoedema is a lesion with grayish-white color. Its location is mainly on the buccal mucosa. Sandstead and Lowe (1953) introduced the description of leukoedema for the first time. They described leukoedema as patches formed around lesions of leukoplakia. It is thought that leukoedema may be a precursor to leukoplakia. Various studies addressed the etiology of leukoedema and agreed that malignancy is not likely to be involved (Archard et al., 1968; Martin et al., 1970; Hammer et al., 1971; Durocher etal., 1972).

\section{Study objectives}

Most epidemiological studies correlated oral mucosal disease with oral cancer and precancerous conditions, but few authors have reported overall oral mucosal lesions or mucosal changes. The present study aimed to investigate the prevalence of some developmental oral mucosal lesions among dental patients wearing dentures who were attending college of dentistry clinics in Aljouf University, and specialized dental center of ministry of health.

\section{Methods and subjects}

We followed a retrospective study design to gather data from files of dental patients with dentures, who were attending specialized dental center of Ministry of Health in Skaka and college of dentistry clinics, Aljouf University.

Study sample included 344 files of dental patients, and study variables included demographic variables (age and gender) and oral lesions including fissured tongue, geographic tongue, Leukoedema, and Fordyce's spots.

\section{Data collection}

We created an excel sheet for all participants including all study variables. All files were eligible if no missing data is noted.

\section{Statistical analysis}

We employed the software SPSS version 20 for data analysis. We presented data as frequencies and percentages for non-continuous variables, and mean and standard deviation for age. One Way Anova analysis was employed to test the effect of both age and gender on oral lesions among dental patients who wear dentures. Further correlational analysis was conducted to examine the possible correlations between variable. Pearson correlation was used. Significance was considered at alpha level $\leq 0.05$. 


\section{Results}

\section{Demographic characteristics of dental patients}

As shown in table 1 , the study included 344 participants, of whom 296 (86\%) were males. The mean age was 51.60+ 3.51years.

Table 1: Demographic characteristics of dental patients $(\mathrm{N}=344)$

\begin{tabular}{|c|c|}
\hline Variable & Description \\
\hline Age (M+SD years) & $51.60+3.51$ \\
\hline Gender (N, \%): & $296(86 \%)$ \\
Male & $48(14 \%)$ \\
Female & \\
\hline
\end{tabular}

\section{Frequency of oral lesions associated with denture wearing}

As demonstrated in table 2, the prevalence of geographic tongue was $11.3 \%$, followed by fissured tongue $10.2 \%$, lukoedema $7.3 \%$ and Fordyce”s grnules (7\%).

Table 2: Frequency of developmental oral lesions associated with denture wearing $(\mathrm{N}=344)$

\begin{tabular}{|c|c|c|}
\hline Oral lesion (developmental lesions) & Frequency & Percentage \\
\hline Fissured tongue: & 35 & 10.2 \\
Yes & 309 & 89.8 \\
No & 39 & \\
Yes & 305 & 11.3 \\
No & 24 & 88.7 \\
\hline Fordyce's granules: & 320 & 7 \\
Yes & & 93 \\
\hline Lo & 25 & 7.3 \\
Yes & 319 & 92.7 \\
\hline
\end{tabular}

\section{The relationship between developmental oral lesions and age}

One way Anova analysis was conducted to investigate the relationship between developmental oral lesions and age. The results revealed that age was significantly associated with fissured tongue $(p=0.04)$, and Fordyce's granules ( $\mathrm{p}=0.003)$ (table 3 ).

Table 3: The relationship between developmental oral lesions and age (One Way Anova)

\begin{tabular}{|c|c|c|c|c|c|}
\hline Oral lesion & $\begin{array}{c}\text { Sum of } \\
\text { squares }\end{array}$ & Df & Mean square & F & P value \\
\hline Fissured tongue & 3.46 & 22 & 0.143 & 1.62 & 0.040 \\
\hline Geographic tongue & 2.606 & 22 & 0.118 & 1.19 & 0.255 \\
\hline Fordyce's granules & 2.82 & 22 & 1.28 & 2.108 & 0.003 \\
\hline Lukoedema & 1.96 & 22 & 0.089 & 1.344 & 0.141 \\
\hline
\end{tabular}

\section{The relationship between oral developmental lesions and gender}

As shown in table 4, none of the oral developmental lesions was significantly associated with gender ( $p>0.05$ for all oral lesions). 
Table 4: The relationship between developmental oral lesions and gender (One Way Anova)

\begin{tabular}{|c|c|c|c|c|c|}
\hline Oral lesion & $\begin{array}{c}\text { Sum of } \\
\text { squares }\end{array}$ & Df & Mean square & F & P value \\
\hline Fissured tongue & 0.03 & 1 & 0.03 & 0.329 & 0.567 \\
\hline Geographic tongue & 0.287 & 1 & 0.287 & 2.861 & 0.092 \\
\hline Fordyce's granules & 0.66 & 1 & 0.66 & 1.014 & 0.315 \\
\hline Lukoedema & 0.66 & 1 & 0.66 & 0.094 & 0.760 \\
\hline
\end{tabular}

\section{The correlation between study variables}

As shown in tables 5 and 6, using Pearson correlation showed there was a significantly positive correlation between age and Fordyce's granulation (Pearson $=0.121, \mathrm{p}=0.025$ ). No other significant correlations were shown.

Table 5: The Pearson correlation between age and oral developmental lesions

\begin{tabular}{|c|c|c|}
\hline Variable & Pearson & P value \\
\hline Fissured tongue & -0.072 & 0.181 \\
\hline Geographical tongue & -0.018 & 0.736 \\
\hline Fordyce's granulations & 0.121 & 0.025 \\
\hline Leukoedema & 0.050 & 0.352 \\
\hline
\end{tabular}

Table 6: The Pearson correlation between gender and oral developmental lesions

\begin{tabular}{|l|l|l|}
\hline Variable & Pearson & P value \\
\hline Fissured tongue & $\mathbf{0 . 0 3 1}$ & $\mathbf{0 . 5 6 7}$ \\
\hline Geographical tongue & $\mathbf{- 0 . 0 9 1}$ & $\mathbf{0 . 0 9 2}$ \\
\hline Fordyce's granulations & $\mathbf{0 . 0 5 4}$ & $\mathbf{0 . 3 1 5}$ \\
\hline Leukoedema & $\mathbf{0 . 0 1 7}$ & $\mathbf{0 . 7 6 0}$ \\
\hline
\end{tabular}

\section{Discussion}

The present study was conducted to determine the prevalence of some developmental oral lesions among a sample of dental patients who wear dentures and who were attending college of dentistry clinics in Aljouf University. Developmental oral lesions included fissured tongue, geographic tongue, Fordyce's granules, and leukoedema.

The data of the present study showed that about $10 \%$ of dental patients had fissured tongue. It seems that the prevalence of fissured tongue has increased overtime in Saudi Arabia. According to the study of AlMobeeriek and AlDosari (2009), the prevalence of fissured tongue was $1.4 \%$. Other studies reported varied rates of prevalence of fissured tongue. At global level, fissured tongue is considered a prevalent tongue disorder with a prevalence of $28 \%$ among elderly Thai (Jainkittivonget al., 2002), while it was about 27\% among Amazonians (Santos et al., 2004). The prevalence of fissured tongue was reported to be $45.7 \%$ in Jordan (Darwazeh and Pillai, 1993). These variations could be justified due to the different methodologies used by different researchers. 
The prevalence of geographic tongue in the present study was about $11 \%$ of dental patients wearing dentures. According to the study of Rezaei et al (2015), the prevalence of geographic tongue was about $7 \%$ in Iran. Other studies reported the prevalence of geographic tongue to be $2 \%$ among people in the United States (Greenburg et al., 2014).

The prevalence of Fordyce's granules was 7\% among dental patients in our study. Previous studies showed a large prevalence of this lesion $80 \%$ among patients (Dover et al., 1996; Drore and Sexton, 1996; Elder, Elenistas and Ragsdale, 1997; Hashimoto and Lever, 1999). In another study conducted in Kuwait, Ali et al (2013) showed a prevalence of this lesion to be about $20 \%$.

The prevalence of leukoedema in the present study was $7 \%$. In a previous study in Saudi Arabia, Al-Mobeeriek and AlDosari (2009) reported a 3.4\% prevalence of leukoedema. Another prevalence of leukoedema was reported by Mani (1985) in Saudi Arabia to be 8.3\%.

The results of current study using Pearson correlation test showed a significantly positive correlation between Fordyce's granulation and age $(\mathrm{p}=0.025)$. This finding is in line with other studies including Jahanbani et al (2009) who reported a positive relationship between some oral developmental lesions including Fordyce's and age and they expressed their opinions as that oral lesions exist since birth or may evident in later life.

\section{Conclusion}

The data of the present study showed that developmental oral lesions among dental patients wearing dentures exist with varying rates of prevalence as well as it provides valuable basic data about the prevalence of oral mucosal lesions among patients seeking dental care in Aljouf area.

\section{References:}

Ahmed TSS, Priore JD, Seykora JT (2009). Tumors of the appendages. In: Elder DE, Elenitsas R, Johnson BL, Murphy GF, editors. Lever's histopathology of the skin. 10th ed. Philadelphia: Lippincott Williams \& Wilkins, 872-873.

Archard JA, Carlson KP, Stanley HR (1968). Leukoedema of the human oral mucosa. Oral Surg Oral Med Oral Pathol, 25:71 7-728.

Axell T, Henricsson V. Leukoedema (1981).An epidemiologic study with special reference to the influence of tobacco habits Commun Dent Oral Epidemiol; 9: 142-6.

Ayah H Musaad, Amal H Abuaffan, Eman Khier (2015). Prevalence of Fissured and Geographic Tongue Abnormalities among University Students in Khartoum State, Sudan. Enz Eng 5: 137. doi:10.4172/2329-6674.1000137. 
Azizah Al-Mobeeriek, Abdullah M. AlDosari (2009). Prevalence of oral lesions among Saudi dental patients. Ann Saudi Med, 29(5): 365-368.

Cawson RA (2008) Cawson's Essentials of Oral Pathology and Oral Medicine, (8thedn).

Darwazeh AM, Pillai K (1993). Prevalence of tongue lesions in 1013 Jordanian dental outpatients. Community Dent Oral Epidemiol, 21(5):323-4. dos Santos PJ, Bessa CF, de Aguiar MC, do Carmo MA (2004). Crosssectional study of oral mucosal conditions among a central Amazonian Indian community, Brazil. J Oral Pathol Med, 33(1):7-12.

Dover J, Arndt K, LeBoit PE, et al (1996). Pocket Guide to Cutaneous Medicine and Surgery. Philadelphia: WB Saunders, 513-31.

Drore E, Sexton J (1996). Disorders of oral membranes. In: Arndt KA, LeBoit PE, Robinson JK, et al. Cutaneous Medicine and Surgery. Philadelphia: WB Saunders, 2:1323-39.

Durocher RT, Thalman R, Ginseppe F (1972). Leukoedema of the oral mucosa. J Am Dent Assoc, 85:1 105-1109.

Elder D, Elenistas R, Ragsdale BD (1997). Tumors of the epidermal appendages. In: Elder D, Elenistas R, Jaworsky C, et al., eds. Lever's Histopathology of the Skin, 8th ed. Philadelphia: Lippincott-Raven, 747803.

Fatemeh Rezaei, Mina Safarzadeh, Hamidreza Mozafari, Payam Tavakoli (2015). Prevalence of Geographic Tongue and Related Predisposing Factors in 7-18 Year-Old Students in Kermanshah, Iran 2014. Global Journal of Health Science, 7(5): 91-95.

Fordyce JA (1986). A peculiar affection of the mucous membrane of the lips and oral cavity. J Cutan Dis, 14, 413-419.

Greenburg, M., Glick, M. (2014). Burket's Oral Medicine (9th ed., pp.103104). Hamilton: BC Decker Inc. http://dx.doi.org/10.1038/sj.bdj.4810224

Hammer JE, Mekta FS, Pindborg JJ, Daftary DK (1971). An epidemiologic and histopathologic study of leukoedema among 50915 rural Indian villagers. Oral Surgery, 32:58-63.

Hashimoto K, Lever WF (1999). Tumors of skin appendages. In: Freedberg IM, Eisen AZ, Wolff K, et al., eds. Fitzpatrick's Dermatology in General Medicine, 5th ed. New York: McGraw-Hill, 1, 890-914.

Jahanfar Jahanbani, Leiv Sandvik, Torstein Lyberg, Eva Ahlfors (2009). Evaluation of Oral Mucosal Lesions in 598 Referred Iranian Patients. The Open Dentistry Journal, 3, 42-47.

Jainkittivong A, Aneksuk V, Langlais RP (2002). Oral mucosal conditions in elderly dental patients. Oral Dis, 8(4):218-23.

James WD, Berger TG, Elston DM (2006). Andrew's disease of the skin. Clinical dermatology. 10th ed. Philadelphia: WB Saunders, 800. 
Ji Hyun Lee, Ji Hae Lee, Na Hyun Kwon, Dong Soo Yu, Gyong Moon Kim, Chul Jong Park, Jeong Deuk Lee, Si Yong Kim (2012). Clinicopathologic Manifestations of Patients with Fordyce's Spots. Ann Dermatol, 24 (1): 103106.

Jorge Ocampo-Candiani, Adriana Villarreal-Rodri'Guez, Alba G. Quin Ones-Ferna ' Ndez, Maira E. Herz-Ruelas, Javier Rui' Z-Esparza (2003). Treatment of Fordyce spots with CO2 laser. Dermatol Surg, 29:869-871. Khozeimeh F, Rasti G (2006) The prevalence of tongue abnormalities among school children in Borazjan, Iran. Dental Research Journal 3: 1-6.

Kullaa-Mikkonen A. (1988). Familial study of fissured tongue Scand J Dent Res; 96: 366-75.

Langlais, R.P., Miller, C.S., Nield-Gehrig, J.S., (2009). Color Atlas of Common Oral Diseases, fourth ed. Lippincott Williams \& Wilkins, Illinois.

M. Goswami, A. Verma, M. Verma (2012). Benign migratory glossitis with fissured tongue. Journal of Indian Society of Pedodontics and Preventive Dentistry, 30 (2): 173-175.

Mani NJ (1985). Preliminary report on prevalence of oral cancer and precancerous lesions among dental patients in Saudi Arabia. Community Dent Oral Epidemiol., 13(4):247-8.

Martin JL, Buenahora AM, Bolden TE (1970). Leukoedema of the buccal mucosa. The Meharri-Dent, 29:7-9.

Martin JL. (1997). Leukoedema: an epidemiological study in white and African Americans J Tenn Dent Assoc; 77: 18-21.

Mohammad Ali, Bobby Joseph, Devipriya Sundaram (2013). Prevalence of oral mucosal lesions in patients of the Kuwait University Dental Center. Saudi Dent J. 25(3): 111-118.

Nevelle BW, Damm DD, Allen CM, Bouquot JE (2004). Oral and Maxillofacial Pathology, (2dedn), Saunders New Delhi India.

Reichart PA, Mohr U, Srisuwan S, Geerlings H, Theetranont C, Kangwanpong T.(1987). Precancerous and other oral mucosal lesions related to chewing, smoking and drinking habits in Thailand Community Dent Oral Epidemiol; 15: 152-60.

Reichart PA. (2000). Oral mucosal lesions in a representative cross-sectional study of aging Germans Commun Dent Oral Epidemiol; 28: 390-8.

Rioboo-Crespo Mdel R, Planells-del Pozo P, Rioboo-García R (2005). Epidemiology of the most common oral mucosal diseases in children. Med Oral Patol Oral Cir Bucal 10: 376-387.

Sadler TW (2011) Head and Neck: Langman's Medical Embrylogy, (10thedn), Lippincott Williams \& Wilkins, USA.

Sandstead HR, Lowe JW (1953). Leukoedema and keratosis in relation to leukoplakia of the buccal mucosa in man. J Natl Cancer Inst, 14:423-427. 
Shafer WG, Hine MK, Levy BM(1983). A textbook of oral pathology First chapter. (4th ed.), Philadelphia: WB Saunders Co.

Taylor RS, Perone JB, Kaddu S, Kerl H (2007). Appendage tumors and hamartomas of the skin. In: Wolff K, Goldsmith LA, Katz SI, Gilchrest BA, Paller AS, Leffell DJ, editors. Fitzpatrick's dermatology in general medicine. 7th ed. New York: McGraw-Hill, 1085.

van Wyk CW(1985). An investigation into the association between leukoedema and smoking J Oral Pathol; 14: 491-9 